\title{
Homing in on Early Homo
}

\section{Citation}

Lieberman, Daniel E. 2007. Homing in on early Homo. Nature 449: 291-292.

\section{Published Version}

doi:10.1038/449291a

\section{Permanent link}

http://nrs.harvard.edu/urn-3:HUL.InstRepos:3743589

\section{Terms of Use}

This article was downloaded from Harvard University's DASH repository, and is made available under the terms and conditions applicable to Other Posted Material, as set forth at http:// nrs.harvard.edu/urn-3:HUL.InstRepos:dash.current.terms-of-use\#LAA

\section{Share Your Story}

The Harvard community has made this article openly available.

Please share how this access benefits you. Submit a story.

\section{Accessibility}


1. Rando, T. A. Nature 441, 1080-1086 (2006)

2. Nijnik, A. et al. Nature 447, 686-690 (2007)

3. Rossi, D. J. et al. Nature 447, 725-729 (2007).

4. Chambers, S. M. et al. PLoS Biol. 5, e201 (2007)

5. Brack, A. S. et al. Science 317, 807-810 (2007)

6. Finkel, T. \& Holbrook, N. J. Nature 408, 239-247 (2000).
7. Lombard, D. B. et al. Cell 120, 497-512 (2005)

8. Shizuru, J. A., Negrin, R. S. \& Weissman, I. L. Annu. Rev. Med. 56, 509-538 (2005).

9. Dumble, M. et al. Blood 109, 1736-1742 (2007)

10. Janzen, V. et al. Nature 443, 421-426 (2006)

11. Tothova, Z. et al. Cell 128, 325-339 (2007).

\title{
PALAEOANTHROPOLOGY
}

\section{Homing in on early Homo}

\author{
Daniel E. Lieberman
}

\section{Newly described fossils from Georgia in Eurasia and from Kenya shed more light on the earliest members of the genus Homo. These finds indicate that there was considerable variability in their size and shape.}

The fossil record of human evolution is like a pointillist painting: one sees a different picture close up from when one stands back. For years, students of human evolution have tended to prefer standing back when considering the evolution of the genus Homo from the genus Australopithecus, by contrasting what came before with what came after. Two sets of discoveries now help us to look more closely at the complex transition from Australopithecus to Homo. One of the papers concerned is by Lordkipanidze and colleagues (page 305 of this issue $)^{1}$, and deals with postcranial bones (those other than the cranium) from Georgia, Eurasia. The other, by Spoor and colleagues ${ }^{2}$, was published in Nature on 9 August and describes cranial material from Kenya.

In terms of the big picture, the transition to Homo was one of the most substantial in human evolution. The time before then was the era of the australopiths. This diverse group of species had brains $400-550 \mathrm{~cm}^{3}$ in volume (only slightly larger than that of a chimpanzee), big cheek teeth, and massive faces adapted to generate and withstand large chewing forces. Australopiths also had many adaptations for upright bipedalism. But they were chimpanzee-sized (100-150 cm tall, weighing $30-50 \mathrm{~kg}$ ), and retained some features useful for climbing trees, such as relatively long arms, upwardly oriented shoulders and long, curved digits.

Sometime after the transition came Homo erectus. This species first appeared in Africa about 1.9 million years ago, and quickly moved out of Africa by 1.8 million years ago. It had a bigger brain, a less snout-like, vertical face, and small, nearly human-sized teeth. A spectacular skeleton, of a juvenile male from Nariokotome, Kenya, dating to 1.5 million years ago, came to epitomize our view of the species as having a very modern body: tall $(160-185 \mathrm{~cm})$, large (50-70 kg), with long legs, and otherwise only subtly different from your body or mine ${ }^{3}$. Homo erectus also seems to have resembled modern humans in having low levels of sexual dimorphism, with males being about 10-20\% larger than females.
When viewed up close, however, the Australopithecus-Homo transition has always been murky. One problem is that we don't know enough about Homo habilis, the putative ancestor of $H$. erectus. In addition, early $H$. erectus fossils are quite variable, and the more we look, the more we find contrasts with later hominins (the formal term for a species in the human lineage). For example, their rate of development was rapid and chimp-like, rather than slow and extended as in modern humans ${ }^{4}$. Also, brain size relative to body size in the earliest $H$. erectus fossils is not much different from that of many australopiths or H. habilis ${ }^{5}$. Finally, the earliest non-African fossils of Homo from Dmanisi, Georgia, which are dated to 1.77 million years ago, resemble $H$. erectus in many respects. But they are highly variable, and more in the size range of $H$. habilis than of $H$. erectus ${ }^{6,7}$.

The new discoveries ${ }^{1,2}$ further highlight the transitional and variable nature of early Homo. Lordkipanidze and colleagues ${ }^{1}$ describe several postcranial fossils from Dmanisi, including partial skeletons of an adolescent associated with a previously reported cranium (D 2700), some limb bones from an adult associated with a massive, previously reported jaw (D 2600), and some foot bones from two smaller adults. In many respects, the fossils resemble modern humans and the Nariokotome $H$. erectus skeleton. The adult's limb proportions are quite modern, with a relatively long femur compared with the humerus, and a tibia/femur ratio similar to that of modern humans from Europe. The feet have a welldeveloped arch and are at least as modern as those of another early Homo foot, $\mathrm{OH}$ 8, from Olduvai Gorge in Tanzania ${ }^{8}$.

Other details, however, are less human-like. Most importantly, the Dmanisi individuals' stature and body mass are smaller than those of the Nariokotome boy. The larger adult would have weighed $48-50 \mathrm{~kg}$ and stood $147-166 \mathrm{~cm}$ tall. The adolescent would have weighed $40-43 \mathrm{~kg}$ and been $145-161 \mathrm{~cm}$ tall, so its adult weight and stature would have been even greater. Estimates of relative brain size are in the range of Australopithecus, well below those of later $H$. erectus and modern humans.

Other differences are also apparent. In modern humans, the elbow joint is typically rotated relative to the shoulder joint, so that the forearm naturally hangs with the palms facing inwards; but the new Dmanisi humeri lack torsion, so their palms would have been oriented more forwards. Lack of humeral torsion, a highly plastic and variable feature, suggests something different about the shoulder in these specimens. In addition, although the adolescent's collar-bone is of normal length for a 15-16-year-old human ${ }^{9}$, and the shoulder joint faces sideways (though at the more vertical end of human variation), other aspects of shoulder-blade shape seem to be primitive. New analyses of the Nariokotome boy also suggest a lack of humeral torsion ${ }^{10}$.

Evidence that early Homo was less modern and more variable than sometimes supposed is also bolstered by Spoor and colleagues' finds from Lake Turkana, Kenya ${ }^{2}$. One of the fossils, KNM-ER 42700, is a beautiful

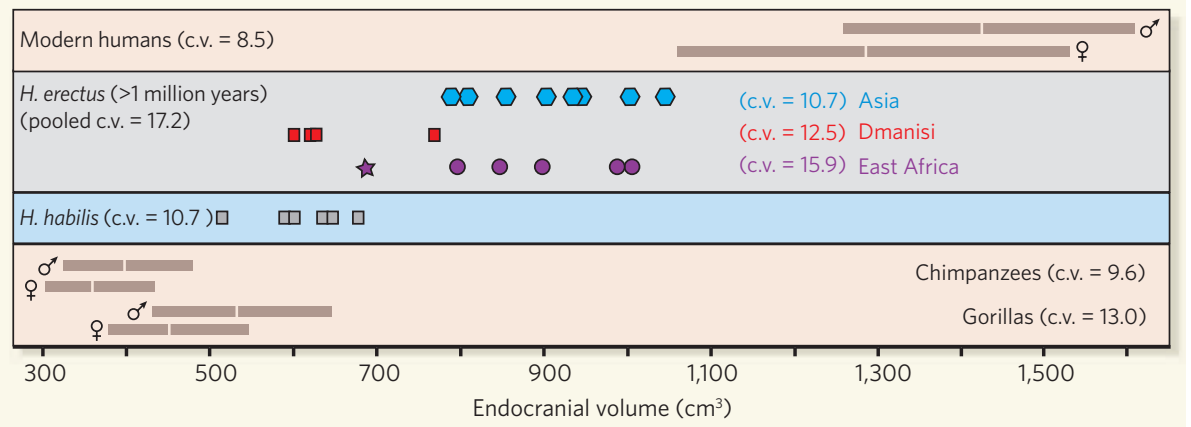

Figure 1 | The wide range of brain sizes in early Homo. Brain sizes (as endocranial volume) of Homo habilis, and of Homo erectus fossils more than 1 million years old, compared with those of modern humans and extant great apes (chimpanzees and gorillas). Data are from refs 1, 13 and 14. The Dmanisi crania and the new KNM-ER $42700 \mathrm{H}$. erectus cranium from Kenya (star) ${ }^{2}$ have smaller brains than most other $H$. erectus specimens. Furthermore, including them in the same species as other fossils attributed to $H$. erectus yields a coefficient of variation (c.v.) of 17.2, much higher than those of modern humans and great apes, even in highly sexually dimorphic species such as gorillas. Grey bars indicate the $\mathbf{9 5 \%}$ confidence interval around the means for each sex in the modern human and great ape samples. Values for c.v. are standard deviations as a percentage of the mean, and are corrected for sample size. 
partial cranium, lacking most of the face, dated to 1.55 million years ago. The fossil's endocranial volume (the volume occupied by the brain inside the cranium) is only $691 \mathrm{~cm}^{3}$, but its shape is mostly typical of larger $H$. erectus crania when adjusted for size. Comprehensive comparative analyses have yet to be undertaken, but the fossil's similarity in size and shape to Dmanisi crania such as D 2700 and to other African fossils attributed to $H$. erectus suggests that these fossils belong to the same species. If so, then early $H$. erectus was not only quite widespread but also unusually variable in both body and brain size (Fig. 1).

Explaining the variation is a challenge. One possibility is that some of it is ecogeographic - that the Dmanisi specimens were simply smaller than their African relations. Alternatively, the Dmanisi fossils may be examples of a different species. In either case, early Homo probably had substantial levels of sexual dimorphism, as we see in Australopithecus. My hunch is that the Dmanisi and early African H. erectus fossils represent different populations of a single, highly variable species. But this hypothesis needs to be tested with comprehensive three-dimensional analyses of scaling and variation (something that will be expedited once computed tomography scans and casts of the fossils are made public).

New discoveries are often most valuable because of the research they stimulate. Basic questions include how many species are represented by the various fossils and how they are related to each other. In some respects, $H$. habilis looks like a good candidate as the ancestor of $H$. erectus: it has a vertical face, teeth of intermediate size between those of Australopithecus and $H$. erectus, and an intermediatesized brain. But the oldest fossils definitively attributed to $H$. habilis are 1.9 million years old, and thus no older than the oldest $H$. erectus fossils. Moreover, Spoor et al. ${ }^{2}$ also report a new $H$. habilis upper jaw dated to 1.44 million years ago, extending the species' temporal overlap with $H$. erectus. Clearly, we need to find and focus more on other fossils older than 2 million years, such as a 2.33-million-year-old upper jaw (AL 666) from Hadar, East Africa, that is possibly H. habilis ${ }^{11}$.

In addition, how behaviourally modern was early H. erectus? The species had small teeth suggesting a more human-like diet, and relatively long legs and other features suited to walking and running ${ }^{12}$. But they matured more rapidly than we do, and big increases in absolute and relative brain size evolved well after the species originated, perhaps as they became more proficient hunters. Homo erectus also might have been more sexually dimorphic. This has implications for reconstructing how much energy this species spent on reproduction, how frequently they spaced births, and aspects of social organization such as levels of male-male competition. Finally, there are other anatomical differences in the upper body and elsewhere that need to be studied for their significance. Looking more closely at details of the long, complex, but highly consequential transformation from Australopithecus to Homo promises to reveal a rich and intriguing picture.

Daniel E. Lieberman is in the Departments of

Anthropology, and Organismic and Evolutionary

Biology, Harvard University, Cambridge,

Massachusetts 02138, USA.

e-mail:danlieb@fas.harvard.edu

1. Lordkipanidze, D. et al. Nature 449, 305-310 (2007).

2. Spoor, F. et al. Nature 448, 688-691 (2007).

3. Walker, A. \& Leakey, R. E. F. (eds) The Nariokotome Homo

erectus Skeleton (Harvard Univ. Press, 1993)

4. Dean, C. et al. Nature 414, 628-631 (2001).
5. Wood, B. A. \& Collard, M. Science 284, 65-71 (1999).

6. Rightmire, G. P., Lordkipanidze, D. \& Vekua, A. J. Hum. Evol. 50, 115-141 (2006).

7. Lordkipanidze, D. et al. Anat. Rec. 288A, 1146-1157 (2006)

8. Harcourt, W. E. \& Aiello, L. J. Anat. 204, 403-416 (2004).

9. Scheuer, J. L. \& Black, S. M. Developmental Juvenile Osteology (Academic, London, 2000).

10. Larson, S. G. et al. J. Hum. Evol. doi:10.1016/ j.jhevol.2007.060.003 (2007).

11. Kimbel, W. H., Johanson, D. C. \& Rak, Y. Am. J. Phys. Anthropol. 103, 235-262 (1997).

12. Bramble, D. M. \& Lieberman, D. E. Nature 432, 345-352 (2004).

13. Holloway, R. L., Broadfield, D. C. \& Yuan, M. S. The Human Fossil Record Vol. 3. Brain Endocasts: The Paleoneurological Evidence (Wiley-Liss, New York, 2004).

14. Tobias, P. V. The Brain in Hominid Evolution (Columbia Univ Press, New York, 1971).

\section{CATALYSIS}

\section{Raising the gold standard}

\section{A. Stephen K. Hashmi}

\section{Gold is the current star of metal catalysis, but most gold catalysts cannot control which mirror-image version of a molecule forms during a reaction. The answer lies with the positive catalyst's negative counter-ion.}

Catalysts are crucial to almost every area of chemistry, often enabling reactions to occur that would otherwise be impossible. Even better, some catalysts can control molecular chirality - they determine which of two mirror-image versions a reaction product will take. Most soluble catalysts of this type are complexes, in which ligand molecules bind tightly to a transition metal; if these complexes are positively charged, the negative counter-ion generally has little effect on the chiral outcome of the reaction. But reporting in Science, Toste and colleagues ${ }^{1}$ describe excellent chiral control in organic reactions catalysed by cationic gold complexes that have chiral counter-ions. If the same principle can be extended to other metals, this discovery could spark a revolution in catalysis, with potential applications for synthesis and the chemical industry.

Many three-dimensional molecules are chiral - they can exist in two forms known as enantiomers that are not superimposable on each other. Each enantiomer may have different properties, which is often of great significance in biology, medicine or materials science. This creates a challenge for chemists: how to devise enantioselective syntheses of such compounds in which the formation of one of the enantiomers is highly preferred. Nature uses enzymes for this purpose, and antibodies can also be developed as catalysts for synthetic reactions. But enzymes and antibodies are complex molecules with high molecular weights. Chemists prefer to use smaller, more easily available catalysts, such as transition-metal complexes or small organic molecules (organocatalysts).

Gold is the latest metal to enter the arena of transition-metal catalysis ${ }^{2,3}$. Gold catalysts have developed impressively over the past few years, and have already provided some valuable contributions. Early examples ${ }^{4,5}$ used cationic gold complexes that incorporated phosphorus-containing ligands known as phosphines, in combination with non-chiral counter-ions. Most gold catalysts still conform to this design. Despite the success of gold catalysts, surprisingly few enantioselective gold-catalysed reactions have been reported.

Toste and colleagues ${ }^{1}$ now describe cationic gold complexes with chiral, negatively charged counter-ions that are based on a phosphate group. In several different reactions commonly catalysed by gold complexes, the authors used their catalysts to obtain chiral products with large excesses of one enantiomer over the other (Fig. 1a). The yields and enantiomeric ratios of these reactions far exceed the high standards required for successful chiral reactions, even when 'problematic' reagents were used that do not react under previously available conditions. This impressive chiral induction is a direct result of using a chiral counter-ion.

The authors found that the enantioselectivity of their reactions was enhanced if the cationic gold complex incorporated a chiral ligand - but only if the 'correct' enantiomer of that ligand was used. Perhaps most strikingly, the authors observed that the influence of the counter-ion can be stronger than the influence of chiral ligands covalently bound directly to the gold centre, which flies in the face of accepted chemical wisdom.

The idea of using counter-ions in catalysts to induce chirality is not new - the strategy has already been successfully used in organocatalysis $^{6}$. The basic principle has even been established in transition-metal catalysis with copper complexes, although the 